\title{
MAIS EDUCAÇÃO, MAIS DOAÇÕES DE ÓRGÃOS
}

\author{
More instruction, more organ donations
}

Taise Ribeiro Morais', Maricelma Ribeiro Morais², Wullo Magalhães Diógenes ${ }^{3}$

\begin{abstract}
RESUMO
Após o desenvolvimento de técnicas cirúrgicas mais avançadas e do surgimento de novos imunossupressores, o transplante de órgãos estabeleceu-se como tratamento de escolha para doenças terminais. Um dos principais fatores limitantes do aumento da captação de órgãos para o transplante é a falta de informação tanto por parte da população quanto por parte dos profissionais de saúde envolvidos. O objetivo do presente estudo é tecer considerações acerca de como pessoas com maior nível de escolaridade parecem ter melhor aceitação sobre doação de órgãos. Dessa forma, a presente revisão enfocará a necessidade de educar indivíduos, buscando aumentar o número de captação de órgãos e promover maior esclarecimento da população acerca do processo de doação e transplante de órgãos e tecidos.
\end{abstract}

Descritores: Doação de Órgão, Educação da População, Capacitação Profissional

1 Central de Transplantes da Paraíba, Núcleo Regional de Campina Grande - PB;

2 Universidade Estadual da Paraíba - Campina Grande - PB

${ }^{3}$ Universidade Federal de Campina Grande - PB.

Correspondência:

Taise Ribeiro Morais

Rua Montevidéu, 634 - Prata

CEP: 58108-660 - Campina Grande - PB

Tel.: 83 9932-0978

E-mail: taise_morais@hotmail.com

Recebido em: 18.05.2007
O transplante e a doação de órgãos humanos são temas polêmicos, que têm despertado interesse e discussões. A falta de esclarecimento e o caráter sensacionalista do noticiário sobre tráfico de órgãos contribuem para aumentar dúvidas e tornar permanentes mitos e preconceitos.

A doação de órgãos e tecidos é vista pela sociedade em geral como um ato de solidariedade e amor por parte de familiares. No entanto, ela exige a tomada de decisão num momento de extrema dor e angústia causados pelo impacto da notícia da morte, do sentimento de perda e pela interrupção inesperada de uma trajetória de vida. ${ }^{1}$

Hoje, com a modificação dos critérios de morte, surgem o conceito de morte encefálica e a possibilidade de utilização de órgãos e tecidos do doador. Quando não há um bom entendimento do processo de doação de órgãos, os familiares dos possíveis doadores sentem-se apreensivos, em dúvida e indecisos no momento da doação, por ser um assunto sobre o qual não têm muito esclarecimento. ${ }^{1}$

A recusa familiar representa um grande entrave à realização dos transplantes, sendo também um dos principais fatores responsáveis pela escassez de órgãos e tecidos para transplantes. As famílias que compreendem bem o diagnóstico de morte encefálica são mais favoráveis à doação de órgãos, em comparação com famílias que acreditam que a morte só ocorre após a parada cardíaca. Sendo assim, a falta de informação reduz drasticamente o número de pacientes beneficiados pela recepção de um órgão. ${ }^{2}$

Apesar da divulgação de informações ser feita por pessoas responsáveis, precisamos educar também os profissionais de saúde, uma vez que eles interferem diretamente na tomada de decisão da família do provável doador.

A literatura é pródiga em referências demonstrando que os meios de comunicação de massa, apesar de sua grande penetração em âmbito nacional e mundial não são os mais adequados para promover o 
esclarecimento necessário sobre temas polêmicos como é, entre outros, o da doação de órgãos. Ao contrário, muitas vezes a forma, simbologia e repertório utilizados pelos meios de comunicação de massa causam mais celeuma e confusão do que esclarecimentos. ${ }^{3}$

Estudo realizado na Espanha constatou que muitas informações provenientes da mídia poderiam ser uma alternativa para o esclarecimento de dúvidas. Entretanto, por vezes esta reproduz informações distorcidas, superficiais e preconceituosas incapazes de modificar comportamentos negativos relacionados à doação de órgãos. ${ }^{4}$

Pesquisa realizada com pessoas que freqüentavam postos de saúde na Espanha apontou que apenas 7\% dos entrevistados receberam informações sobre transplante de profissionais que proporcionavam cuidados primários de saúde. Embora as informações negativas tenham sido bastante absorvidas, o estudo indica que mesmo em pequena proporção, a informação positiva gerou uma nova forma de interpretar a doação de órgãos. ${ }^{5}$

Ressaltamos aqui a importância da discussão do assunto "doação de órgãos" com amigos e familiares, pois, quando bem instruídas, as pessoas são capazes de promover discussões, o que pode ser considerado promoção de doação.

O indivíduo contrário à doação de órgãos aparece em estudos como sendo: homem ou mulher com idade acima de 45 anos com baixo nível educacional, que não conhece o conceito de morte encefálica, tem parceiro contra a doação de órgãos, não é favorável à doação de sangue e tem medo da manipulação do corpo após a morte. As principais razões para não aceitar a doação foram o desconhecimento de como se tornar doador e o medo de diagnóstico equivocado de morte. ${ }^{6}$

Frente a essa realidade, o profissional de saúde deve atuar como educador, visando modificar a opinião pública quanto a conceitos errôneos. Porém, as crenças desfavoráveis só poderão ser modificadas quando os educadores estimularem a população a participar de debates sobre transplantes de órgãos e a legislação pertinente.

Modificar a realidade existente implica também em desenvolver programas planejados e avaliados dentro de um processo educativo contínuo, respaldado por referenciais teóricos e modelos cientificamente reconhecidos, destinados a todos os segmentos da comunidade.

Portanto, faz-se necessária uma exortação ao poder público, para que considere a falta de insumos à prática da doação de órgãos como um problema real, e que sejam incluídas atividades educativas prioritárias acerca de transplantes nos programas do Governo e nas políticas de cuidados com a saúde.

Uma vez que a doação de órgãos no Brasil depende exclusivamente da permissão familiar, campanhas que busquem maior esclarecimento da população sobre o conceito de morte encefálica e especialmente que incentivem as pessoas a manifestar o desejo de ser doador e discutir sua decisão com a família são estratégias importantes para amenizar esse problema.

\section{ABSTRACT}

After the development of surgical techniques and the arrival of new immunosuppressant medications, the organ transplantation was established as the elected treatment for end-stage diseases. One of the main limiting factors to increase the organ captivation is the lack of information both among the population and the health professionals involved. The purpose of this study is to discuss some considerations on how people with higher education level seem to better accept the organ donation. This review will aim the need to educate individuals, seeking to increase the amount of organ donation, thus promoting a higher clarification level among the population on the organ and tissue donation and transplantation.

Keywords: Organ Donation, Population Education, Professional Training

\section{REFERÊNCIAS BIBLIOGRÁFICAS}

1. Alencar SCS. Doação de órgãos e tecidos: a vivência dos familiares de crianças e adolescentes doadores. Dissertação (mestrado) - Universidade Federal do Paraná, Setor de Ciências da Saúde, Programa de Pós-Graduação em Enfermagem: Paraná, 2006.

2. Siminoff LA, Mercer MB, Arnold R. Families understanding of brain death. Prog Transplant. 2003;13(3):218-24.

3. Moraes MW, Gallani MCBJ, Meneghin P. Crenças que influenciam adolescentes na doação de órgãos. Rev Esc Enferm USP: São Paulo, 2006;40(4):484-92.
4. Conesa C, Ríos A, Ramírez P, Canteras M, Rodríguez MM, Parrilla P. Influence of different sources of information on attitude toward organ donation: a factor analysis. Transplant Proc. 2004;36:1245-8

5. Traiber C, Lopes MHI. Educação para doação de órgãos. Scientia Medica, Porto Alegre: PUCRS, v. 16, n. 4, out./dez. 2006.

6. Martinez JM, Martin A, Lopez JS. Spanish public opinion concernig organ donation and transplantation. Med Clin. 1995;105:401-6. 